The Effects of Strategic HR System Differentiation on Firm Performance and Employee Outcomes

Joseph A. Schmidt

Dionne Pohler

Chelsea R. Willness

University of Saskatchewan

\begin{abstract}
Author Notes
Joseph A. Schmidt and Chelsea R. Willness, Edwards School of Business, University of Saskatchewan; Dionne Pohler, Johnson-Shoyama Graduate School of Public Policy, University of Saskatchewan.
\end{abstract}

This research was funded in part by the Canadian Tourism Human Resource Council and the Social Sciences and Humanities Research Council of Canada (\#430-2014-00383).

This is the pre-peer reviewed version of the following article: Schmidt, J. A., Pohler, D., \& Willness, C. R. (2018). Strategic HR system differentiation between jobs: The effects on firm performance and employee outcomes. Human Resource Management, 57(1), 65-81, which has been published in final form at https://doi.org/10.1002/hrm.21836. This article may be used for non-commercial purposes in accordance with Wiley Terms and Conditions for Use of Self-Archived Versions. 


\begin{abstract}
The purpose of this research was to understand the extent to which firms apply different human resource management systems to different occupations within the same organization (HR differentiation), and how this influences both firm and employee outcomes. We conducted two studies pertaining to these questions. The first study was based on data collected from managers and the results showed that firms differentiate their HR investments based on the strategic value of occupations, which was further associated with the human capital of those occupations; differentiation in human capital was also associated with firm performance. The second study was based on data obtained from non-management employees. The findings of this study indicated that employees who were recipients of less HR system investment had lower fairness perceptions, which were further associated with turnover intentions and organizational citizenship behavior. Although the evidence from these studies suggests that firms may realize benefits from HR differentiation, managers should carefully consider how to balance the effects of differentiation on firm performance and employee well-being before implementing such systems.
\end{abstract}

Keywords: human resource management; high performance work systems; human capital; turnover; fairness perceptions; organizational citizenship behavior 


\section{The Effects of Strategic HR System Differentiation on Firm Performance and Employee Outcomes}

A core objective of strategic human resource (HR) management research is to understand how firm investment in HR systems and practices affects organizational performance (Delery \& Doty, 1996). However, one area that has received relatively little theoretical and empirical attention is the extent to which firms make differential investments across occupation groups within the same organization, and what impact this has on employee attitudes, behavioral intentions, and on firm performance. One of the earliest perspectives in strategic HR management, the universal approach, proposed that greater organizational investment in HR would unilaterally improve firm performance by increasing the ability and motivation of all employees in the organization (Huselid, 1995). In contrast, scholars emphasizing a contingency approach have shown that an important factor for understanding the HR-performance linkage is the alignment between the type and amount of HR investment with the firm's competitive environment and operational strategies (e.g., Datta, Guthrie, \& Wright, 2005; Delery \& Doty, 1996; Youndt, Snell, Dean, \& Lepak, 1996). Theory in this latter tradition, as well as limited empirical research, has more recently focused on the application of different HR systems across different occupations within the same firm based on the strategic value of the occupational skill set required for each occupation, the firm-specific nature of the required skill sets, and the availability of the occupational skills in the labor market (Lepak \& Snell, 1999; 2002; Lepak, Taylor, Tekleab, Marrone, \& Cohen, 2007).

Researchers often apply human capital and cost-benefit arguments to explain why organizational decision-makers differentiate HR investments between occupation groups within the same organization. Lepak and Snell (1999) posited that managers explicitly consider both the 
transaction and labor costs associated with different types of HR systems to determine if HR investments will produce the desired returns. They suggest that occupations that have a greater impact on accomplishing the firm's strategic objectives, or that require unique skill sets, receive potentially greater HR investments, either because they have a disproportionate impact on creating value for the firm, or because it is more difficult to find employees with the relevant skills. Others have applied similar logic to explain why the firm's pivotal talent (Cascio \& Boudreau, 2008) or "A positions” (Huselid, Beatty, \& Becker, 2005) require greater HR investments. Most recently, Kaufman (2015) highlighted the importance of using economicsbased models that precisely explain how the adoption of HR systems is based on considerations of the marginal costs versus the expected marginal returns of the system.

To date, some empirical research has supported these arguments, in that firms differentiate HR systems between occupation groups, with strategically valuable occupations receiving greater investment (Lepak \& Snell, 2002; Lepak et al., 2007). However, the extent to which within-firm HR system differentiation across occupations influences organizational performance has received relatively little attention. Further research is required to develop theory that explicates the consequences of within-firm HR differentiation, both in terms of its effects on firm performance and its influence on employee attitudes and behaviors (Becker \& Huselid, 2006; Huselid \& Becker, 2011; Jackson, Schuler, \& Jiang, 2014).

This is an important line of inquiry because HR system differentiation has the potential to reduce perceptions of fairness (Lepak et al., 2007) and organizational commitment (Marescaux, De Winne, \& Sels, 2013) among employee who receive less favorable outcomes. Human capital and cost-benefit models based on transaction and labor costs, and/or the marginal productivity of employees, do not take into account such potential psychological and behavioral costs associated 
with the adoption of a differentiated HR architecture within the organization. If employees perceive HR differentiation to be unfair, these costs may include lower performance, job withdrawal, decreased citizenship behaviors, and negative reactions including theft and other retaliatory behaviors (Colquitt, Conlon, Wesson, Porter, \& Ng, 2001). Such costs often do not factor in to HR investment decisions because they can be difficult for managers to quantify (Kaufman, 2015). Notwithstanding the potential for these additional psychological and behavioral costs, particularly among those employees who receive fewer investments, the costs that arise from this strategy may still be insufficient to offset the gains that come from higher investments in occupations that make a more valuable contribution to the firm. To date, however, we know little about how employees perceive and respond to this strategic occupation-based differentiation.

We address these gaps in the literature through a two-study approach. In Study 1, we collected data from senior-level managers to test theoretically-grounded hypotheses about the extent to which organizations differentiate HR investments based on the strategic value of occupations, and the association between such HR differentiation and human capital and voluntary turnover (i.e., quit rates). We also examine the extent to which differentiation based on the strategic value of occupations within an organization is associated with overall firm performance. That is, we examined whether or not organizations actually engage in these practices, as the strategic HR literature would suggest they should, and we test whether such differentiation is associated with positive outcomes for the firm.

Looking at the link between HR differentiation and firm performance is only part of the story; employees are a critical linchpin in determining the relative effectiveness of an organization's HR practices. Thus, employee perceptions of HR practices are an important 
mechanism that can explain why HR differentiation and organizational outcomes are connected (or not). In Study 2, we gathered data from front-line employees to test hypotheses derived from the group value model (e.g., Lind, 1995; Tyler, 1989) and the group engagement model (Tyler \& Blader, 2003) about how employees' perceptions of HR differentiation within their organization influences their turnover intentions and willingness to engage in organizational citizenship behaviors, as mediated by their perceptions of fairness. We further tested a moderation effect to determine if the association between HR differentiation and fairness perceptions was contingent on the amount of HR investment in the respondents' own occupation groups.

This research makes three primary contributions. As one of the first studies to test the associations between within-firm occupation-based HR differentiation and human capital, quit rates, perceived financial performance, and employee attitudes and behavioral intentions, this study has the potential to develop theory about how the HR system architecture influences employee- and firm-level outcomes. Second, this research helps bridge the micro/macro divide in the HR literature (Becker \& Huselid, 2006; Paauwe, 2009) by collecting data from both senior managers and front-line employees. The approach allows us to determine the extent to which the two groups have similar perspectives about HR differentiation within firms, and if front-line employee perceptions about HR differentiation are consistent with the association between differentiation and firm performance reported by managers.

Finally, the study has practical implications by clarifying the types of costs that need to be considered by organizational decision-makers when determining how to allocate HR investments - for instance, whether or not managers should account for psychological costs, such as employee perceptions of unfairness, that are likely more challenging to quantify. Even if these costs are not found to be important, strategic HR research has not explicitly highlighted the 
potential for conflicting interests between organizations and at least a subset of employees in "less valuable" occupations. If, as has been argued by others, balancing the interests of owners and management with the interests of front-line employees is an important normative goal in managing the employment relationship (Budd, 2004; Pfeffer, 2010; Pohler \& Luchak, 2014), we need more empirical studies that explicitly highlight the impact of the tradeoffs that are being made by each party.

\section{Study 1}

The objective of Study 1 was to gather data about the antecedents and consequences of within-firm HR system differentiation from the perspective of managers. We first tested theoretical propositions about the extent to which firms differentiate their HR system investments based on the strategic value of occupations to the organization. We further tested the association between HR system investment and human capital and turnover rates at the occupation level. Finally, we examined the effects of strategic HR differentiation on firm performance.

\section{HR System Differentiation between Occupations within the Same Establishment}

Strategic HR theorists adopting a universal or "best practices" approach have shown that appropriate investments in HR will increase performance across all organizations (Huselid, 1995). Investments in what have been called high commitment HR systems or high performance work systems (HPWS) - often defined as “flexible job assignments, rigorous and selective staffing, extensive training and development, developmental and merit-based performance appraisal, competitive compensation, and extensive benefits" (Takeuchi, Lepak, Wang, \& Takeuchi, 2007: 1069) - have been argued to increase performance of the organization's entire workforce which ultimately enhances firm financial performance (Pfeffer, 1998). Consistent with 
this approach, scholars applied the Ability-Motivation-Opportunity model in a recent metaanalysis to show that overall investments in HPWS influence a variety of firm-level outcomes. Well-aligned HPWS investments that enhance employees' skills and abilities, provide employees with extrinsic incentives to perform, and give them the autonomy and opportunities to apply their skills are associated with a variety of firm-level outcomes including human capital, voluntary turnover, and financial performance (Jiang, Lepak, Hu, \& Baer, 2012).

Other scholars, following the contingency persepctive, propose that HPWS investments will produce the greatest returns when there is differentiation within the organization's HR system (e.g., Lepak \& Snell, 1999), and that the extent of HR system differentiation may be more or less appropriate depending on the strategy employed by the organization or the characteristics of the organization's occupation groups (Becker \& Huselid, 2006). Lepak and Snell's (1999) original conceptualization of a differentiated HR system proposed that firms determine the extent of HR investment based on the strategic value of human capital (i.e., potential to contribute to firm competitive advantage) and the uniqueness of the required skills (i.e., firm-specificity or availability in the labor market) of different occupations within the same firm. For unique and strategically valuable jobs, they argue that firms should invest in highcommitment HR systems that are focused on long-term employee development, involvement in decision-making, and retention - an HR system comparable to HPWS as defined by others (e.g., Takeuchi et al., 2007). Conversely, occupations that are less strategically valuable and/or not unique should be managed with HR systems that are focused on shorter-term performance or compliance, which often require less resource-intensive investments.

From the cost-benefit and marginal productivity perspectives, such differentiated HR system configurations enhance firm performance for two reasons. First, intensive HR 
investments should lead to greater performance among employees in occupations that directly contribute to strategy execution and value creation for the firm. Second, the organization can reduce overall costs, further enhancing firm performance, by investing less in occupations that are on the margins of the value chain.

Although studies are limited, early empirical research in this area provided some support for the idea that firms apply different HR system configurations to different types of jobs (Jackson, Schuler, \& Rivero, 1989; Schuler \& Jackson, 1987). Lepak and Snell (2002) tested their theoretical propositions and demonstrated that firms employ different HR system configurations based on the strategic value and uniqueness of occupations. More recently, Lepak et al. (2007) did not find that strategically valuable employees always receive greater HR investments than less strategic, or peripheral, employees in manufacturing firms; however, they did find that strategically valuable employees received more HR investments than their less strategically valuable counterparts in non-manufacturing firms. None of this research examined the effects of HR differentiation on firm performance.

Although Lepak and Snell describe how four different types of HR systems should be configured based on the strategic value and uniqueness of occupations, we hereafter focus only on the effects of strategic value and HPWS differentiation within firms to maintain theoretical and analytical parsimony. This is also consistent with the approach of many researchers who primarily emphasize the role of an occupation's strategic value in determining differentiated HR investments within firms (Cascio \& Boudreau, 2008; Huselid et al., 2005; Huselid \& Becker, 2011). Furthermore, the uniqueness of employee skill sets are mostly influenced by factors external to the organization - such as the availability of and competition for the skills in the labor market - that may or may not impact employee ability to contribute to firm performance. Given 
that our sample is non-manufacturing, and mostly non-unionized, we expect that firms will differentially invest in HPWS based on the strategic value of occupation groups:

Hypothesis 1. Within organizations, there is a positive association between the strategic value of occupation groups and HPWS investment in those occupation groups.

Scholars have argued that a well-designed HPWS influences firm performance via collective employee behaviors. That is, a HPWS creates a workforce that possesses the ability, motivation, and opportunity to create sustained competitive advantage, adding value to the firm through important workforce outcomes that exceed the cost of investment in the HPWS (e.g., Becker, Huselid, Pickus, \& Spratt, 1997; Jiang et al., 2012; Takeuchi et al., 2007). Investment in HPWS thus enhances human capital - defined as "knowledge, skills, and abilities that have economic value to the firm" (Lepak \& Snell, 2002: 519) - which ultimately enhances firm performance. Meta-analytic evidence has supported this assertion, demonstrating that HPWS are positively associated with firm-level human capital (Jiang et al., 2012). While these effects were observed at the firm level, we expect to observe similar effects within firms between different occupation groups. That is, where greater HPWS investments are made for certain occupation groups within the organization, employees in those occupations will possess the abilities, motivation, and opportunities to make more significant contributions to firm performance (i.e., collective human capital will be higher in these occupations). Consistent with the rationale for Hypothesis 1, firms differentiate HPWS investments between occupation groups based on strategic value, which is further associated with human capital differentiation between occupation groups. Therefore, the association between occupation group strategic value and occupation group human capital is mediated by HPWS investment. 
Hypothesis 2. Within organizations, there is a positive association between HPWS investment in occupation groups and the human capital of those occupation groups. Hypothesis 3. Within organizations, the positive association between the strategic value and human capital of occupation groups is mediated by HPWS investments in those occupation groups.

Scholars have also applied social exchange theory (Blau, 1964) to explain how investments in HPWS have engendered greater loyalty and lower turnover among employees. Positive exchange relationships are defined by mutual trust that both parties will reciprocally exchange benefits over the long term. Employees are likely to perceive that higher investments in their development, compensation, and job design are personally beneficial, which will enhance their perceptions of a positive social exchange relationship with their employer and increase their felt obligation to reciprocate (Takeuchi et al., 2007). One way that employees can reciprocate is by remaining loyal to the organization. Moreover, if employees leave the firm they forego the benefits from the HPWS, and it can be difficult for employees to know if they will experience the same level of benefits elsewhere (Campbell, Coff, \& Kryscynski, 2012).

Research at the firm-level has indeed linked higher investment in HPWS to lower quit rates (Jiang, et al., 2012; Shaw, Delery, Jenkins, \& Gupta, 1998), especially for HR practices that are primarily focused on enhancing employee well-being (Batt \& Colvin, 2011; Shaw, Dineen, Fang, \& Vellella, 2009). While the aforementioned research examined the effects of HR systems on employee quits at the organization level between firms, we expect to observe similar effects at the occupation level within firms. Firm differentiation in HPWS investments between occupation groups based on strategic value will lead to different quit rates between occupation groups within firms - that is, occupation groups with greater HPWS investments have lower quit rates than 
occupation groups with lower HPWS investments. Reflecting the same logic of Hypotheses 2 and 3 , we tested the following hypotheses:

Hypothesis 4. Within organizations, there is a negative association between HPWS investment in occupation groups and the quit rate of those occupation groups. Hypothesis 5. Within organizations, the negative association between the strategic value of occupation groups and the quit rates of those occupation groups is mediated by HPWS investments in those occupation groups.

Our hypotheses extend Lepak et al.'s $(2002,2007)$ findings by examining the effects of within-firm HPWS differentiation on human capital and quit rates. We also test these effects at the firm level, which further extends past research on both the universal and contingency approaches by determining if firm-level effects hold while controlling for within-firm variance in occupational strategic value, HPWS, human capital, and quit rates. While theory and earlier empirical findings suggest that we will observe similar mediated effects both within and between firms, prior research between firms did not control for within-firm variance in these constructs. Figure 1 shows a depiction of our multilevel model.

\section{HPWS Differentiation and Firm Performance}

The underlying logic of the differentiation approach is that employees in strategically valuable occupations have a disproportionately larger effect on firm performance compared to their less strategically valuable counterparts (Lepak \& Snell, 1999; 2002); thus, managers decide to make differentiated HPWS investments across occupations within the organization to increase human capital and decrease turnover among strategically valuable employees. If occupation groups differ in their level of strategic value to the organization, uniform HPWS investment across all occupation groups would reduce marginal returns by increasing HR system costs for 
non-strategically valuable employees relative to the benefits they bring to the organization. Assuming that HPWS investments increase human capital and reduce turnover, it is more efficient to make lower HPWS investments in less strategically valuable occupations because the human capital and voluntary turnover among these employees have smaller effects on firm performance than HPWS investments in greater strategically valuable occupations. The differentiation perspective has received increasing theoretical support from scholars who propose that managers should apply a cost-benefit rationale to determine the level of HPWS investments they are willing to make, especially in highly competitive environments (e.g., Kaufman, 2015; Patel \& Cardon, 2010). Following this logic, strategic differentiation is likely to have positive effects on firm performance.

Hypothesis 6: Strategic differentiation in (a) human capital and (b) quit rates are positively and negatively associated with firm performance, respectively.

\section{Study 1 Methods}

\section{Sample and Procedure}

We collected Study 1 data from senior-level managers of organizations in the Tourism industry using two recruitment approaches. First, we sent email invitations to owner/operators or senior managers on the Canadian Tourism Human Resource Council's (CTHRC) email contact list of establishments in the Canadian Tourism sector. Of the 1,447 invitations sent to valid email addresses, 162 organizations provided data about the strategic value, HR practices, human capital, and turnover within each of their organization's occupation groups. Of those, 147 provided establishment-level financial and operational performance data, resulting in an overall response rate of approximately $10 \%$ for this sample. 
We also collected data from the Amazon Mechanical Turk (MTurk) website, which is an online marketplace that allows users to post requests for others to complete tasks in exchange for payment. A number of previous studies have obtained survey data from this website (e.g., Adams, Luevano, \& Jonason, 2014; Greenwood, 2013; Greenwood, Long, \& Dal Cin, 2013). Researchers have found that MTurk samples are generally more demographically diverse (Buhrmaster, Kwang, \& Gosling, 2011; Casler, Bickel, \& Hackett, 2013) and have slightly different personality profiles (Goodman, Cryder, \& Cheema, 2013) than student, community, or other internet panel samples; however, the psychometric properties of survey measures and experimental effects tend to be very consistent with other types of samples (Buhrmaster et al.; Casler et al.; Goodman et al.; Holden, Dennie, \& Hicks, 2013).

Potential respondents were required to pass a "qualification test" before being directed to the online survey. The qualification test confirmed that respondents were residents of Canada or the United States, and were managers or business owners working in the tourism industry. Each of the three qualification questions (residency, position title, industry) presented potential participants with numerous responses in drop-down menus, and the answers required to qualify for the study were not apparent to the test-takers. In total, 207 participants passed the qualification test and completed the survey. The organization sample recruited from both of these sources contained responses from 354 firms.

To examine within-firm variance, we only included organizations that provided data for two or more occupation groups in the analyses; therefore, the final sample was reduced to 657 occupation groups nested within 210 organizations. The average organization size was 56.65 employees $(S D=4.53)$, and 121 organizations were located in Canada, while the remainder were in the United States $(n=89)$. A total of $55.1 \%$ of the respondents were representatives of 
subsidiaries or divisions of a larger parent organization, $11.4 \%$ of respondents were franchise owner/operators, $18.3 \%$ of respondents were owner/operators of independent businesses, $8.1 \%$ of respondents were representatives of a parent organization or worked in corporate headquarters, and $7.1 \%$ of the sample represented another type of organization structure.

\section{Measures}

Respondents were asked to identify occupation groups in their organization and to provide data about HR practices, strategic value, human capital, and voluntary turnover for each relevant group. There were six possible occupation groups to choose from, including positions in management (e.g., Executive Chef, Restaurant and Food Service Manager, General Manager), food service (e.g., Bartender, Food and Beverage / Banquet Server), guest service (e.g., Front Desk Agent, Guest Service Attendant), food preparation (e.g., Cooking Staff, Sous Chef), operations / maintenance (e.g., Landscaping and Grounds Maintenance, Housekeeping Room Attendant), and sales (e.g., Sales Representative). The job exemplars included in each occupation group were derived from the most frequently reported positions in a nationally representative compensation survey of the Canadian Tourism and Hospitality industry as well as input from subject matter experts at the CTHRC. Unless otherwise specified, all the measures described below were completed on a 5 -point Likert scale $(1=$ strongly disagree to $5=$ strongly agree $)$.

HPWS. Respondents completed 15 items from a high-performance work practice measure adapted from Lepak and Snell (2002) and Huselid (1995) for each occupation group relevant to their organization. The measure included four job design items (e.g., "employees in this occupation group....are often asked to participate in work-related decisions," "...are allowed to make necessary changes in the way they perform their work"), three selection items ("when someone needs to be hired in this occupation group...emphasis is placed on identifying the best 
all-around candidate," "...the selection procedure involves the use of more than one type of assessment"), four training items (e.g., "training activities for employees in this occupation group...develop the skills/abilities needed to do their job better," "...help prepare them for future jobs they might want to do in this organization"), two performance management items (i.e., "Performance feedback for employees in this occupation group...is tied to the pay/rewards received," “...emphasizes personal learning and development goals”), and three compensation items (e.g., "compensation/rewards for employees in this occupation group...rewards the development of knowledge, skills, and abilities," “...matches well with the organization's financial performance").

We conducted exploratory principle components analysis with oblique rotation on responses to the 15 HPWS items. Three components had eigenvalues greater than one and inspection of the scree plot indicated a clear three-factor solution that accounted for $54.52 \%$ of the item variance. The factor structure appeared to be consistent with the Ability-MotivationOpportunity model of HR practices (e.g., Jackson et al., 2014; Jiang et al., 2012). All of the training and selection items, one performance management item, and one job design item - each of which addressed improving workforce skill sets - loaded on the first component; thus, this component appeared to represent ability-enhancing HR practices (component loadings ranged from .48 to .82 ). Three of the job design items about providing employees with autonomy loaded on the second component, which appeared to represent opportunity-enhancing HR practices (component loadings ranged from .80 to .87). Finally, all of the compensation items and one performance management item loaded on what appeared to be the component representing motivation-enhancing HR practices (component loadings ranged from .57 to .87 ). The internal 
consistency reliabilities of the components were $.82, .81$, and .79 for the ability-, opportunity-, and motivation-enhancing components, respectively.

Because the ratings of HR practices for each occupation group were nested within organizations, we also conducted confirmatory factor analysis with the "complex" estimation option in MPlus 7.2, which corrects standard errors and the chi-square test of model fit to account for non-independence of observations. The results demonstrated that the three-factor ability-motivation-opportunity enhancing model fit the data reasonably well, $\chi^{2}(99)=170.27, p$ $<.01, \mathrm{CFI}=.96, \mathrm{TLI}=.95, \mathrm{RMSEA}=.03$. To be consistent with past research, we averaged the scores of the three HR practice factors to create a HPWS scale for each occupation group (e.g., Den Hartog, Boon, Verburg, \& Croon, 2013). The ICC(1) for the HPWS scale was .71 indicating that $71 \%$ of the variance in this construct was between organizations.

Strategic value. Respondents completed a six-item scale adapted from Lepak and Snell (2002) about the strategic value of each relevant occupation group to the organization. Sample items include, "competent employees in this occupation group are expected to...contribute to the development of new market/product/service opportunities," and “...improve organizational efficiency and productivity" (within-level $\alpha=.82, \operatorname{ICC}(1)=.47$ ).

Human capital. Human capital for each identified occupation group was measured with a five-item scale developed by Youndt and colleagues (Subramaniam \& Youndt, 2005; Youndt, Subramaniam, \& Snell, 2004). Example items include "employees in this occupation group...are highly skilled," and “...are experts in their particular jobs/functions" (within-level $\alpha=.86$, $\operatorname{ICC}(1)=.49)$. 
Quit rates. For each occupation group, respondents provided the total number of employees who voluntarily quit in the previous year and the total number of employees in each occupation group $(\operatorname{ICC}(1)=.44)$.

Firm performance. We included three questions about firm performance from Delaney and Huselid's (1996) measure wherein respondents were asked to rate their firm's performance in comparison to other firms that do the same kind of work in terms of growth in sales, profitability, and market share. These questions were answered on a five-point Likert scale ranging from $1=$ much worse to $5=$ much better $(\alpha=.89)$. The use of perceptual measures of firm performance is not without precedent (e.g., Delaney \& Huselid, 1996; Gupta, 1987; Gupta \& Govindarajan, 1984, 1986; Takeuchi et al., 2007), and Wall et al. (2004) demonstrated the convergent, discriminant, and construct validity of perceptual performance measures in relation to objective firm performance data.

Control variables. We controlled for the natural logarithm of total employees in each occupation group at the within-firm level (i.e., level 1) because firms may make greater HPWS investments for occupation groups with more employees and, in general, larger firms may have more sophisticated HR systems (Lepak \& Snell, 2002). We also controlled for the time invariant effects of industry subsector by entering three dummy variables for the Food and Beverage, Accommodation, and Recreation and Entertainment sectors (Travel Services was the reference group) at the between-firm level (i.e., level 2). A dummy variable was also entered for the data source (CTHRC contact list vs. Mechanical Turk) at level 2 to control for systemic differences between respondents from each source. Finally, the age of the organization was entered as a control at level 2 because older organizations may have had more opportunities and resources to develop sophisticated HR systems. 


\section{Analysis}

Given the multilevel nature of this data set (occupation groups nested within organizations), we conducted multilevel path analysis with MPlus 7.2 to test the hypotheses. The models test the mediated effects shown in Figure 1 while appropriately partitioning variance to the within- and between-organization levels. The quit outcome variable was overdispersed and censored at zero, so it was left as a count variable and negative binomial regression was conducted for this outcome. The number of employees in each occupation group was log transformed and entered as the offset variable in the negative binomial analyses. This approach converts the counts to log transformed rates and accounts for the fact that some variance in quit counts is based on occupation group size. The bootstrap resampling procedure, to test the significance of indirect (mediated) effects proposed by Preacher and Hayes (2008), cannot be conducted for multilevel models that include negative binomial regression in MPlus; thus, Sobel tests were used to examine the significance of indirect effects at both levels. The level 1 variables were group-mean centered as we were focused on testing differences within organizations at this level.

To test Hypothesis 6, the random slopes for the regressions of human capital on strategic value and quits on strategic value at the within-firm level were estimated. The latent random slope terms were then entered as predictors of firm performance at level 2 along with the controls and the firm-level means of these variables. As an example of how to interpret these effects, a positive association between the random slope term for human capital and firm performance indicates that the larger the within-firm slopes between strategic value and human capital (i.e., the more the strategically valuable occupation groups within firms also have higher levels of human capital), the higher the firm performance. 


\section{Study 1 Results}

The descriptive statistics and correlations among the Study 1 variables are reported in Table 1 and the hypotheses tests with all of the control variables in the model are displayed in Figure 1. The results show that strategic value was positively associated with HPWS, that HPWS was positively associated with human capital within firms, and the test of the indirect effect was also significant $(\gamma=.22$, Sobel test $=4.47, p<.001)$. Thus, Hypotheses 1 through 3 were supported. It was a partial mediation effect, however, because the association between strategic value and human capital remained significant with all of the variables in the model. The association between HPWS and quits was not significant, nor was the indirect effect of strategic value on quits as mediated by HPWS $(\gamma=-.14$, Sobel test $=-1.61, p=.107)$; thus, Hypotheses 4 and 5 were not supported.

It is also important to note that firm-level HPWS investments were associated with firmlevel human capital and quit rates after controlling for within-firm variance in these variables. The results showed that there was a positive association between firm-level HPWS and human capital $(\gamma=.47, p<.001)$ as well as a negative association between HPWS and quits $(\gamma=-.38, p$ $=.002$ ). Furthermore, the indirect effects of firm-level strategic value on human capital and quit rates as mediated by HPWS were also significant $(\gamma=.19$, Sobel test $=4.18, p<.001$ and $\gamma=-$ .16 , Sobel test $=-2.59, p=.010$ for human capital and quit rates, respectively). These findings suggest that higher overall perceptions of strategic value at that firm level are associated with greater HPWS investments, which influence firm-level outcomes over and above within-firm variance in these factors.

Hypothesis 6 states that strategic differentiation in human capital and quit rates is associated with higher firm performance. The results reported in Table 2 show that the human 
capital random slope term was positively associated with firm performance, indicating that higher levels of human capital among strategically valuable employees was associated with higher firm performance. Thus, Hypothesis $6 \mathrm{a}$ was supported. Hypothesis $6 \mathrm{~b}$ was not supported as the quit rate random slope term was not associated with performance. The mean level of HPWS was also associated with firm performance in these models. ${ }^{1}$

In summary, the Hypotheses tests indicate that firms make strategically differentiated HPWS investments, which is further associated with human capital differences between occupation groups. The results indicated that average HPWS investments at the firm-level were positively and negatively associated with the firm's overall human capital and quit rates, respectively, while controlling for within-firm variance in these constructs. Finally, Hypothesis 6 was partially supported in that strategic differentiation in human capital was associated with higher firm performance, but differentiation in quit rates was not. Firm-level HPWS investment was also positively associated with firm performance in these models.

One potential explanation for the Study 1 finding that strategic differentiation in human capital is associated with higher firm performance is that differentiation has no negative impact on employee attitudes and behaviors, and thus there are no hidden costs associated with differentiation. However, this may mask differences in outcomes across employees who either do or do not benefit from the differentiation. Moreover, the results of Study 1 indicate that overall firm-level HPWS investment is associated with firm-level human capital, quit rates, and firm performance, over and above the extent of differentiation within firms. Thus, another potential

\footnotetext{
${ }^{1}$ To check the robustness of these findings, we also tested the associations between the within-firm standard deviations of human capital and quit rates with firm performance. These effects were not significant $(\gamma=.02, p=$ .839 and $\gamma=-.10, p=.175$ for human capital and quit rate standard deviations, respectively). Of note, the standard deviation term only captures overall within-firm variance and not the extent to which variance is based on strategic value. The firm-level average of HPWS was significant in these models $(\gamma=.28, p=.013)$.
} 
explanation is that even though there may be hidden psychological costs of differentiation, these costs may be mitigated by a greater than average universal HR investment across all employees in some firms. Supporting this idea, research has shown that there is a negative effect of pay dispersion on firm performance for firms that compensate their employees below market rates that disappears when employees are compensated above the market (Brown, Sturman \& Simmering, 2003). However, to date there has been very little research on how employees perceive and respond to this strategic occupation-based differentiation. Regardless of any impact on firm performance, this is important for strategic HR scholars understand, as it may indicate a trade-off between the interests of the organization and the interests of employees - particularly those employees in less strategically valuable jobs.

\section{Study 2}

Our objective in Study 2 is to examine employee perceptions and attitudes about the fairness of HPWS differentiation between occupations within the organization, and how these attitudes may impact turnover intentions and organizational citizenship behaviors. However, before we can examine how employee attitudes and behaviors may be impacted by this differentiation, we must first establish whether employees perceive that their coworkers in other occupation groups are indeed subject to different levels of HR investment. Social comparison theory (Festinger, 1954) suggests that people compare themselves to others in order to make relative evaluations about their standing on salient attributes and outcomes. Such comparisons readily occur in the workplace as employees observe and compare the outcomes they receive to those received by others in the organization (e.g., Greeberg, 1988; Greenberg, 1990; Sturman \& Thibodeau, 2001). With regard to HR system investments specifically, research has shown that employees evaluate the favorability of HR practices they receive compared to others in the 
organization (Marescaux et al., 2013). Moreover, employees do not necessarily relegate their comparisons to those in their own occupation group, especially when they work in close proximity with other employees and when information required to make comparisons is easily accessible (Kulik \& Ambrose, 1992). For instance, front-line managers have been shown to assess the external equity of their compensation packages in relation to that of their CEO's (Wade, O’Reilly, \& Pollock, 2006) and Chinese employees have made comparisons to local expatriates, even though they differed on a variety of characteristics (Leung, Zhu, \& Ge, 2009). Employees are also likely to have some understanding of the firm's strategy and will recognize strategic value differences between occupation groups (e.g., the Executive Chef is more strategically valuable than the Dishwasher). Therefore, we posit that employees perceive differences in strategic value and HR investment between occupation groups. Given that the findings from Study 1 and past research (e.g., Lepak \& Snell, 2002) showed that firms strategically differentiate HR investments, we expect to observe a positive association between employee perceptions of the strategic value of occupation groups and HPWS investments in those occupation groups within their organization. We thus propose a hypothesis to replicate the results of the first Hypothesis in Study 1, but from the employees' perspective:

Hypothesis 7: Within organizations, there is a positive association between the strategic value of occupation groups and HPWS investment in those occupation groups.

Some scholars have begun to question the performance benefits of HR system differentiation within firms based on ideas of fairness. Lepak et al. (2007) postulated that extreme differentiation may lead to lower firm performance if perceptions of unfairness cause some employees to withdraw support and assistance to others. Other research shows that the effects of differentiation on employee attitudes and behaviors will depend on whether and to 
what extent an employee benefits from that differentiation. For instance, Marescaux et al. (2013) found a positive association between the perceived favorability of HR outcomes and affective organizational commitment.

The group value model (e.g., Lind, 1995; Tyler, 1989) and its more recent extension, the group engagement model (Tyler \& Blader, 2003), provides a comprehensive explanation of these effects. The group value model focuses on the social antecedents of justice perceptions. It proposes that employees perceive organizational processes and interactions with leaders to be fair when they feel that they are a high status group member (i.e., their standing within the organization is recognized), they are treated respectfully, and decision-makers are neutral and unbiased. The group engagement model extends this reasoning, such that people decide to "invest" their social identities in groups when they perceive that the group treats them fairly and provides them with favorable outcomes. Fair treatment allows people to feel as though their future interactions with the group will be predictable and respectful. The outcomes people receive from a group are symbolic of their status, and the receipt of personally favorable outcomes indicates that their standing within the group is secure. Such conditions cause people to identify with the group, which leads to higher levels of commitment, engagement, and discretionary helping behavior. Research has supported the propositions of both models. In support of the group value model, Tyler (1989) demonstrated that citizens had higher justice perceptions about interactions with police when officers made unbiased decisions, treated citizens respectfully, and conveyed positive messages about their social standing. Blader and Tyler (2009) found support for the group engagement model by showing that social identity judgments mediate the associations between procedural justice and economic outcomes with extra-role behavior. 
According to these models, it is possible that employees will perceive strategic HR differentiation as unfair, especially if they receive lower HR system investment. Recipients of lower investments may perceive that they are low status members of the organization and that the formal processes of the organization are not conducted in their interest, which reduces their perceptions of fairness. As such, employees who receive fewer HR investments are likely to perceive unfairness when the organization strategically differentiates its HR system.

Hypothesis 8: The association between strategic HPWS differentiation in the organization and employee fairness perceptions is moderated by the level of HPWS investment received by the employee. There is a stronger negative association between strategic HPWS differentiation and fairness perceptions when the HPWS investment received by the employee is lower compared to when it is higher.

The group engagement model posits that people will not identify with groups that treat them unfairly, which leads to lower psychological and behavioral engagement. This means that group members are unlikely to engage in discretionary, extra-role behaviors and may seek to leave the organization altogether. Meta-analytic findings have supported these propositions, linking various conceptualizations of justice to organizational commitment, job withdrawal, and organizational citizenship behaviors (Colquitt et al., 2001). Therefore, we expect that employee fairness perceptions will be negatively associated with turnover intentions and positively associated with organizational citizenship behaviors. Given the moderation effect described in Hypothesis 8, we further expect to observe moderated mediation effects (Preacher, Rucker, \& Hayes, 2007), where the mediated effects of HPWS differentiation on turnover intentions and organizational citizenship behaviors through fairness perceptions are further moderated by the level of HPWS investments received by the employee (see Figure 2). 
Hypothesis 9: Fairness perceptions are a) negatively associated with turnover intentions, and $b$ ) positively associated with organizational citizenship behaviors.

Hypothesis 10: The level of HPWS investments received by the employee moderate the effects of HPWS differentiation on (a) turnover intentions and (b) organizational citizenship behaviors as mediated by fairness perceptions. The mediation effects are stronger when the level of HPWS investments received by the employee is lower compared to when it is higher.

\section{Study 2 Methods}

\section{Sample}

The front-line employee sample was recruited from two sources. First, 1,048 people from the Study Response Project's online survey panel database who were employed in the Tourism and Hospitality industry were invited to complete the Study 2 survey. The response rate was $19.56 \%(n=205)$. Participants were also recruited from the MTurk site and, as with the organizational survey, respondents were required to pass a qualification test to ensure that they were currently employed in the Tourism and Hospitality Industry, were residents of Canada or the United States, and were not working in a management position. In all, 389 participants were recruited from this source increasing the initial employee sample to 594. As with the Study 1 data, we only included employees who provided data for two or more occupation groups within their organization, which reduced the sample to 531 occupation groups provided by 197 employees. Most of the respondents were residents of the United States (99\%). Participants had an average of 13.29 years of work experience $(S D=8.55)$ and worked 38.09 hours per week $(S D$ $=11.36)$. 


\section{Measures}

Strategic value and HPWS. As with the Study 1 survey, employees were asked to identify which of the six occupation groups were in their organization and also indicate which occupation group applied to their own position. Respondents then completed the same measures of HPWS practices and strategic value that were used in the Study 1 survey for each of the occupation groups in their organization. The internal consistency reliability was .76 and the ICC(1) was .63 for strategic value. Regarding the HPWS practices, the internal consistency reliabilities for the ability, opportunity, and motivation factors were $.90, .77$, and .86 , respectively. Confirmatory factor analysis also demonstrated that the three factor model fit the data well, $\chi^{2}(99)=232.24, p<.01, \mathrm{CFI}=.97, \mathrm{TLI}=.96, \mathrm{RMSEA}=.04$. As with the Study 1 data, the three HR practice factors were averaged to create a HPWS scale for each occupation group. The $I C C(1)$ value was .78 for HPWS. As described below, respondents also completed measures of their perceptions of overall fairness, organizational citizenship behavior, and turnover intentions that were assessed on a five-point Likert scale $(1=$ strongly disagree to $5=$ strongly agree).

Overall fairness. Employees' perceptions of overall fairness were assessed with three items from a scale developed by Ambrose and Schmidtke (2009). Examples include, "usually, the way things work around here are fair," and "for the most part, this establishment treats its employees fairly." $(\alpha=.82)$.

Turnover intentions. Three items were used to measure turnover intentions based on a measure developed by Meyer, Allen, and Smith (1993; e.g., "I am planning to leave my job for another in the near future," $\alpha=.94)$. 
Organizational citizenship behavior. Six items were used from a scale developed to assess citizenship behavior directed toward the organization (Lee \& Allen, 2002), including "I offer ideas to improve the functioning of the establishment," and "I take action to protect the establishment from potential problems" $(\alpha=.86)$.

Control variables. As in Study 1, three dummy variables for industry subsector were entered (Food \& Beverage, Accommodation, Recreation \& Entertainment) to control for timeinvariant differences between organizations in these different segments (Travel Services was the reference category). We also entered a dummy variable to control for differences related to data source (Study Response Project versus MTurk), and we entered dummy variables for employment status (full-time versus other), employment permanence (permanent employee vs. other), and union membership to control for the potential for varying perspectives from different types of employees.

\section{Analysis}

As with Study 1, this was a multilevel survey where we gathered employee perceptions of strategic value and HPWS offered to multiple occupation groups within their organization, and thus, occupation group ratings of strategic value and HPWS were nested within employees. To test the hypotheses, multilevel path analysis with MPlus 7.2 was conducted so that the variance was appropriately partitioned at the within and between levels. The association between strategic value and HPWS for each occupation group in the respondent's organization was entered at the first level. The level 1 model tests the extent to which respondents perceived that occupation group strategic value and HPWS investments varied in their organizations (Hypothesis 7), allowing us to test whether employees perceived the same differentiation in HR investment between occupation groups based on strategic value that we found in the first study 
from the perspective of managers or business owners. A mediated model was estimated at level 2, where random slopes of strategic value on HPWS estimated at level 1 predicted the respondents' fairness perceptions, which then predicted turnover intentions and OCB. All of the control variables and the organization-level mean HPWS were also entered at level 2. The level 2 model tests the extent to which employee perceptions of strategic HPWS differentiation are associated with turnover intentions and OCB as mediated by fairness perceptions.

\section{Study 2 Results}

The descriptive statistics and correlations for Study 2 variables are reported in Table 3 and Figure 2 displays the results of the Hypotheses tests. Hypothesis 7 states that employees will perceive that their employer differentiates HPWS investment based on the strategic value of occupation groups within the firm, which was supported based on the positive association between strategic value and HPWS at level 1.

Hypothesis 8 states that the association between strategic HPWS differentiation and employee fairness perceptions is moderated by HPWS investment received by the employee. We tested this by examining the interaction between the strategic value-HPWS random slope term and HPWS received by the employee on fairness perceptions at level 2 . The interaction effect was significant $(\gamma=.75, p=.013)$. As displayed in Figure 3, Hypothesis 8 received support because follow-up tests showed a stronger negative association between the random slope term and fairness when the HPWS received by the employee was one standard deviation below the mean $(\gamma=-1.35, p=.009)$. This means that the fariness perceptions for these employees decreased the more that their firms strategically differentiated HPWS investments between occupation groups. The association was not significant when HPWS received by the employee was one standard deviation above the mean $(\gamma=-.04, p=.775)$. 
Hypotheses 9a and 9b, respectively, state that there will be a negative association between fairness and turnover intentions and a positive association between fairness and OCB. Both of these hypotheses were supported. Hypotheses $10 \mathrm{a}$ and $10 \mathrm{~b}$ state that the associations between strategic HPWS differentiation with turnover intentions and OCB as mediated by fairness perceptions are further moderated by the level of HPWS received by the employee. Hypothesis 10a was supported: the indirect effect was significant when HPWS received by the employee was one standard deviation below the mean $(\gamma=.65$, Sobel test $=2.32, p=.020)$, but not when it was one standard deviation above the mean $(\gamma=.02$, Sobel test $=.29, p=.772)$. The indirect effect of strategic HPWS differentiation on OCB was significant when HPWS received by the employee was one standard deviation below the mean $(\gamma=-.81$, Sobel test $=-2.16, p=$ $.030)$, but not when it was one standard deviation above the mean $(\gamma=-.03$, Sobel test $=-.28, p=$ .780). Thus, Hypothesis $10 \mathrm{~b}$ was also supported. ${ }^{2}$

\section{Discussion}

A core objective of strategic HR theory and research is to understand how and under what conditions investment in HR affects firm performance. The universal perspective advocates for greater investment in high-performance work systems across the organization to enhance productivity through increased human capital outcomes. More recently, contingency perspectives suggest that firm investment in HPWS depends on the industry and the strategy of the firm, and also that firms should differentiate HPWS investments within the firm depending on the strategic value of different employee groups. Prior to our current studies, there was limited empirical

\footnotetext{
${ }^{2}$ As with Study 1, we checked the robustness of the effects by substituting the within-firm standard deviation of HPWS investments in place of the latent random slope term for all of the hypothesized models. The pattern of significant effects remained the same in these analyses. The interaction between the HPWS standard deviation and the level of HPWS received by the employee on fairness perceptions was significant $(\gamma=.19, S E=.09, p=.026)$. The paths from fairness to turnover intentions and OCB were also significant in these models $(\gamma=-.53, S E=.07, p<$ .001 and $\gamma=.64, S E=.09, p<.001$ for turnover intentions and OCB, respectively). The pattern of moderated mediation effects was also consistent with the tests of Hypothesis 10.
} 
evidence to determine how employees perceive such practices, and the effects on their attitudes and behaviors intentions toward the organization. In particular, some employees may perceive differentiated HPWS investments as unfair, and it was not clear whether the benefits of HR system differentiation within the firm outweigh the potential psychological and behavioral costs of such practices. To address these gaps, we examined how HR system differentiation impacts both organizational and employee outcomes, thus putting some of the core assumptions of standard economic approaches to invesment in HR to the test.

We conducted two empirical studies in the tourism industry, in turn accounting for organization- and employee-level perspectives. In Study 1, we tested the extent to which firms differentiate HPWS investments based on the strategic value of the occupation groups in the organization and the impact of differentiation on human capital and turnover of employees in different occupation groups. We also tested the extent to which strategic differentiation impacts overall firm performance. The results of Study 1 show that firms do differentiate their HPWS investments based on the strategic value of occupation groups - they are investing more in their pivotal talent, or "A positions" - and doing so increased human capital for those employee groups. This was, in turn, associated with better firm performance; however, firm-level HPWS investments and human capital were also associated with firm performance over and above the extent of within-firm differentiation. Thus, our first study provides evidence that the link between differentiation and firm performance is more complex than existing models may suggest.

In particular, standard human capital and cost-benefit models do not account for the potential psychological and behavioral costs associated with using a differentiated approach to HR. Therefore, we proposed that examining employee reactions may provide more insight into 
the Study 1 results. In Study 2, we tested theoretically-grounded hypotheses derived from the group value and group engagement models (Lind, 1995; Tyler \& Blader, 2003), because accounting for employee perceptions of fairness and their resulting behaviors can provide a deeper understanding of the effects and implications of differentiated HR practices. First, our findings showed that employees perceived HPWS differentiation based on the strategic value of occupation groups within their organization, thus confirming the organization-level findings from Study 1 from the employees' perspective and providing an indication that broad social comparisons occur among employees with respect to the HR practices in their workplace. We also found that, for employees who received fewer HPWS investments, there was an association between HPWS differentiation and employees' turnover intentions and willingness to perform organizational citizenship behaviors, and that these effects could be at least partly explained by fairness perceptions. Specifically, high differentiation resulted in greater turnover intentions and lower OCB, particularly for employees who do not benefit from differentiation.

Strategic HR scholars who have argued for a contingency perspective have traditionally focused on understanding how optimal design in HPWS leads to greater organizational performance, assuming that the causal link is improved employee outcomes. However, our results show the importance of linking macro-level theory and research with micro-level effects of employee behavior to understand the complex relationships between HPWS and employee attitudes and behaviors. In essence, organizations are differentiating between occupation groups because they believe it makes rational economic sense to do so, and the results provided support for this perspective.

The tests of the firm-level effects also provide support for the universal perspective, painting an intriguing picture about the processes through which HR investments influence firm 
and employee outcomes. More specifically, firm-level HPWS investment and human capital were associated with firm performance over and above strategic differentiation in human capital. These results may suggest that universally high HPWS investments across all occupation groups may generate returns for the firm by offsetting the psychological costs of HR system differentiation. Future research should seek to extend these findings by clarifying the longer-term costs and returns of HPWS investment, including how the financial benefits of differentiation may be offset by the possible negative effects on the well-being of some employees.

The results also showed that firm-level strategic value was associated with overall HPWS investments, suggesting that managers may decide to make higher universal HPWS investments when they perceive that all occupation groups generate some value for the firm. This may imply that management philosophy and culture influence decisions about how to design the HR archicture. While theory and research suggest that HR systems influence culture (e.g., Bowen \& Ostroff, 2004; Yeung, Brockbank, and Ulrich, 1991), future research should seek to understand the extent to which existing management philosophies and organization culture influence the adoption of different types of HR systems. Moreover, Researchers should also seek to understand the how managers balance these considerations with marginal productivity returns that result from HR system investment (Kaufman, 2015).

Finally, the results support recent calls from scholars that an important normative goal in both the study and practice of the employment relationship is to understand how to balance the sometimes conflicting interests of management and employees (Budd, 2004). Pfeffer (2010) reviewed the negative psychological and physical health outcomes experienced by employees when the primary criteria that determine HR policy are employee efficiency and productivity. Similarly, Pohler and Luchak (2014) demonstrated that both firms and employees experience 
positive outcomes when firms effectively balance attempts to improve efficiency with HR practices that are equitable and involve employees in decision-making. Our results demonstrate that strategic HR differentiation can lead to negative outcomes for some employees, highlighting potential ethical considerations that should be addressed by managers when deciding how to balance interests when making HR investments. Future strategic HR research should seek to more explicitly highlight these trade-offs for managers.

\section{Limitations}

The primary limitation of these studies is that they were cross-sectional, which does not allow us to rule out some alternative explanations for the findings, and provides a static association between the variables at the point our data was collected. Furthermore, the nature of our sample - the tourism industry - may reduce the generalizability of our findings. The tourism industry has a higher than average turnover rate, and a higher proportion of non-strategic workers compared to other industries. There may also not be as much benefit arising from differentiation between occupations in this industry, given that the jobs being performed may be less complex than in many other industries. Finally, the relatively small sample size of occupation groups within firms may have led to reduced statistical power to detect the effects of strategic differentiation in quit rates on firm performance in Study 1. Although the associations between HPWS differentiation and employee attitudes were quite robust in Study 2, future research should seek to replicate the Study 1 results with larger occupation-group sample sizes. In spite of these limitations, this research was one of the first to apply multilevel modeling and obtain perspectives from both management and employees to understand how HR differentiation influences firm- and employee-level outcomes. 


\section{Implications for Practice}

Our research has a number of practical applications in the design and implementation of HR systems. First, managers should carefully consider the costs and benefits of HR initiatives, and not limit this analysis to include easily quantifiable costs. Cascio and Boudreau (2008) present a compelling framework by which to understand the financial returns of HR systems (e.g., selection, training, wellness programs) as well as employee attitudes and behaviors (e.g., employee engagement, job performance, and turnover) that are often deemed challenging to quantify. Their methods do not directly account for the potential psychological costs of differentiated HR systems; thus, it may be necessary to integrate approaches that quantify the costs of differentiation on employee attitudes with an assessment of potential benefits that are realized from such an approach.

Second, firms that decide to make differentiated HR system investments need to consider how to improve fairness perceptions among employees who receive fewer benefits. Our results and others (Maresceaux et al., 2013) suggest that the HR investments may be a salient aspect for social comparison among employees. It can be challenging for organizations to maintain secrecy about HR differentiation given that many aspects of the HR system - including training, performance management, and career development processes - are likely quite visible to employees. Consequently, organizations may seek to communicate openly with all employees about the differentiated HR system in order to curb employees' perceptions of injustice. Research has demonstrated that distributive justice perceptions are associated with intrinsic motivation when organizations are transparent about the compensation system, whereas the effect of procedural justice on motivation is negligible in such situations (Hartmann \& Slapnicar, 2012). As such, firms should seek to emphasize how the criteria for determining differentiated 
HR investments is aligned with the amount of investments provided to each occupation group when crafting communications about the HR system.

Finally, it is important for management to provide positive messages about employees' status within the organization, particularly for employees who receive fewer investments. Given that the level of HR investment likely has symbolic meaning about employees' social standing within the organization, positive messaging that reinforces employees' sense of dignity and status may mitigate the negative effects of HR differentiation on employee fairness perceptions.

\section{Conclusions}

Strategic HR theory and research suggests an advantageous cost-benefit trade-off for within-firm HPWS differentiation in that the savings from making unequal within-firm investments based on the strategic value of occupation groups outweigh the potential costs. However, past research has not adequately considered the implications of perceived unfairness and lower human capital, particularly among less strategically valuable employees. The results of our studies suggest that such practices can influence firm performance, and that the overall level of HR investments also influence performance over and above strategic differentiation. Moreover, HR differentiation has a negative effect on job attitudes for many employees, which may offset some of the benefits realized from this approach. Researchers and practitioners should continue to carefully examine HPWS differentiation given the important implications not only for organizational performance, but also for employee outcomes. 


\section{References}

Adams, H. M., Luevano, V. X., \& Jonason, P. K. (2014). Risky business: Willingness to be caught in an extra-pair relationship, relationship experience, and the dark triad. Personality and Individual Differences, 66, 204-207.

Ambrose, M. L., \& Schminke, M. (2009). The role of overall justice judgments in organizational justice research: A test of mediation. Journal of Applied Psychology, 94, 491-500.

Batt, R., \& Colvin, A. J. (2011). An employment systems approach to turnover: Human resources practices, quits, dismissals, and performance. Academy of Management Journal, 54, 696-717.

Becker, B. E., \& Huselid, M. A. (2006). Strategic human resources management: Where do we go from here? Journal of Management, 32, 898-925.

Becker, B. E., Huselid, M. A., Pickus, P. S., \& Spratt, M. F. (1997). HR as a source of shareholder value: Research and recommendations. Human Resource Management, 36, $39-47$.

Blader, S. L., \& Tyler, T. R. (2009). Testing and extending the group engagement model: Linkages between social identity, procedural justice, economic outcomes, and extrarole behavior. Journal of Applied Psychology, 94, 445-464.

Blau, P. M. (1964). Exchange and power in social life. New York: Wiley.

Bowen, D. E., \& Ostroff, C. (2004). Understanding HRM-firm performance linkages: The role of the "strength" of the HRM system. Academy of Management Review, 29, 203-221.

Brown, M., Sturman, M., \& Simmering, M. (2003). Compensation policy and organizational performance: The efficiency, operational, and financial implications of pay levels and pay structure. Academy of Management Journal, 46, 752-762.

Budd, J. W. (2004). Employment with a human Face: Balancing efficiency, equity, and voice. 
Ithaca, NY: Cornell University Press.

Buhrmester, M., Kwang, T., \& Gosling, S. D. (2011). Amazon's Mechanical Turk: A new source of inexpensive, yet high-quality, data? Perspectives on Psychological Science, 6, 3-5.

Campbell, B. A., Coff, R., \& Kryscynski, D. (2012). Rethinking sustained competitive advantage from human capital. Academy of Management Review, 37, 376-395.

Cascio, W., \& Boudreau, J. (2008). Investing in people: Financial impact of human resource initiatives. Upper Saddle River, NJ: Pearson Education.

Casler, K., Bickel, L., \& Hackett, E. (2013). Separate but equal? A comparison of participants and data gathered via Amazon's MTurk, social media, and face-to-face behavioral testing. Computers in Human Behavior, 29, 2156-2160.

Colquitt, J. A., Conlon, D. E., Wesson, M. J., Porter, C. O., \& Ng, K. Y. (2001). Justice at the millennium: A meta-analytic review of 25 years of organizational justice research. Journal of Applied Psychology, 86, 425-445.

Datta, D. K., Guthrie, J. P., \& Wright, P. M. (2005). Human resource management and labor productivity: Does industry matter? Academy of Management Journal, 48, 135-145.

Delaney, J. T., \& Huselid, M. A. (1996). The impact of human resource management practices on perceptions of organizational performance. Academy of Management Journal, 39, 949-969.

Delery, J. E., \& Doty, D. (1996). Modes of theorizing in strategic human resource management: Tests of universalistic, contingency, and configurational performance predictions. Academy of Management Journal, 39, 802-835.

Den Hartog, D. N., Boon, C., Verburg, R. M., \& Croon, M. A. (2013). HRM, communication, satisfaction, and perceived performance: A cross-level test. Journal of Management, 39, 
1637-1665.

Festinger, L. (1954). A theory of social comparison processes. Human Relations, 7, 117-140.

Goodman, J. K., Cryder, C. E., \& Cheema, A. (2013). Data collection in a flat world: The strengths and weaknesses of Mechanical Turk samples. Journal of Behavioral Decision Making, 26, 213-224.

Greenberg, J. (1988). Equity and workplace status: A field experiment. Journal of Applied Psychology, 73, 606-613.

Greenberg, J. (1990). Employee theft as a reaction to underpayment inequity: The hidden cost of pay cuts. Journal of Applied Psychology, 75, 561-568.

Greenwood, D., Long, C. R., \& Dal Cin, S. (2013). Fame and the social self: The need to belong, narcissism, and relatedness predict the appeal of fame. Personality and Individual Differences, 55, 490-495.

Greenwood, D. N. (2013). Fame, Facebook, and Twitter: How attitudes about fame predict frequency and nature of social media use. Psychology of Popular Media Culture, 2, 222236.

Gupta, A. K. (1987). SBU strategies, corporate-SBU relations, and SBU effectiveness in strategy implementation. Academy of Management Journal, 30, 477-500.

Gupta, A. K., \& Govindarajan, V. (1984). Business unit strategy, managerial characteristics, and business unit effectiveness at strategy implementation. Academy of Management Journal, $27,25-41$.

Gupta, A. K., \& Govindarajan, V. (1986). Resource sharing among SBUs: Strategic antecedents and administrative implications. Academy of Management Journal, 29, 695-714.

Hartmann, F., \& Slapničar, S. (2012). Pay fairness and intrinsic motivation: The role of pay 
transparency. International Journal of Human Resource Management, 23, 4283-4300.

Holden, C. J., Dennie, T., \& Hicks, A. D. (2013). Assessing the reliability of the M5-120 on Amazon's Mechanical Turk. Computers in Human Behavior, 29, 1749-1754.

Huselid, M. A. (1995). The impact of human resource management practices on turnover, productivity, and corporate financial performance. Academy of Management Journal, 38, $635-672$.

Huselid, M. A., \& Beatty, R. W., \& Becker, B. E. (2005). A players or A positions? The strategic logic of workforce management. Harvard Business Review, 83, 110-117.

Huselid, M. A., \& Becker, B. E. (2011). Bridging micro and macro domains: Workforce differentiation and strategic human resource management. Journal of Management, 37, 421-428.

Jackson, S. E., Schuler, R. S., \& Jiang, K. (2014). An aspirational framework for strategic human resource management. Academy of Management Annals, 8, 1-56.

Jackson, S. E., Schuler, R. S., \& Rivero, J. (1989). Organizational characteristics as predictors of personnel practices. Personnel Psychology, 42, 727-786.

Jiang, K., Lepak, D. P., Hu, J., \& Baer, J. C. (2012). How does human resource management influence organizational outcomes? A meta-analytic investigation of mediating mechanisms. Academy of Management Journal, 55, 1264-1294.

Kaufman, B. E. (2015). Market competition, HRM, and firm performance: The conventional paradigm critiqued and reformulated. Human Resource Management Review, 25, 107125.

Kulik, C. T., \& Ambrose, M. L. (1992). Personal and situational determinants of referent choice. Academy of Management Review, 17, 212-237, 
Lee, K., \& Allen, N. J. (2002). Organizational citizenship behavior and workplace deviance: The role of affect and cognitions. Journal of Applied Psychology, 87, 131-142.

Lepak, D. P., \& Snell, S. A. (1999). The human resource architecture: Toward a theory of human capital allocation and development. Academy of Management Review, 24, 31-48.

Lepak, D. P., \& Snell, S. A. (2002). Examining the human resource architecture: The relationships among human capital, employment, and human resource configurations. Journal of Management, 28, 517-543.

Lepak, D. P., Taylor, M. S., Tekleab, A. G., Marrone, J. A., \& Cohen, D. J. (2007). An examination of the use of high-investment human resource systems for core and support employees. Human Resource Management, 46, 223-246.

Leung, K., Zhu, Y., \& Ge, C. (2009). Compensation disparity between locals and expatriates: Moderating the effects of perceived injustice in foreign multinationals in China. Journal of World Business, 44, 85-93.

Lind, E. A. (1995). Justice and authority relations in organizations. In R. S. Cropanzano \& K. M. Kacmar (Eds.), Organizational Politics, Justice, and Support: Managing the Social Climate of the Workplace (pp. 83-96). Westport, CT: Quorum Books.

Marescaux, E., De Winne, S., \& Sels, L. (2013). HR practices and affective organisational commitment: (when) does HR differentiation pay off? Human Resource Management Journal, 23, 329-345.

Meyer, J. P., Allen, N. J., \& Smith, C. A. (1993). Commitment to organizations and occupations: Extension and test of a three component conceptualization. Journal of Applied Psychology, 78, 538-551. 
Paauwe, J. (2009). HRM and performance: Achievements, methodological issues and prospects. Journal of Management Studies, 46, 129-142.

Patel, P., \& Cardon, M. (2010). Adopting HRM practices and their effectiveness in small firms facing product-market competition. Human Resource Management, 49, 265-290.

Pfeffer, J. (2010). Building sustainable organizations: The human factor. Academy of Management Perspectives, 24, 34-45.

Pfeffer, J. (1998). The human equation. Boston: Harvard University Business School Press. Pohler, D., \& Luchak, A. (2014). Balancing efficiency, equity and voice: The impact of unions and high involvement work practices on work outcomes. Industrial and Labor Relations Review, 67, 1063-94.

Preacher, K. J., \& Hayes, A. F. (2008). Asymptotic and resampling strategies for assessing and comparing indirect effects in multiple mediator models. Behavior Research Methods, 40, 879-891.

Preacher, K. J., Rucker, D. D., \& Hayes, A. F. (2007). Addressing moderated mediation hypotheses: Theory, methods, and prescriptions. Multivariate Behavioral Research, 42, $185-227$.

Schuler, R. S., \& Jackson, S. E. (1987). Organizational strategy and organizational level as determinants of human resource management practices. Human Resource Planning, 10, 125-140.

Shaw, J. D., Delery, J. E., Jenkins, G., \& Gupta, N. (1998). An organization-level analysis of voluntary and involuntary turnover. Academy of Management Journal, 41, 511-525. 
Shaw, J. D., Dineen, B. R., Fang, R., \& Vellella, R. F. (2009). Employee-organization exchange relationships, HRM practices, and quit rates of good and poor performers. Academy of Management Journal, 52, 1016-1033.

Sturman, T. S., \& Thibodeau, R. (2001). Performance undermining effects of baseball free agent contracts. Journal of Sport \& Exercise Psychology, 23, 23-36

Subramaniam, M., \& Youndt, M. A. (2005). The influence of intellectual capital on the types of innovative capabilities. Academy of Management Journal, 48, 450-463.

Takeuchi, R., Lepak, D. P., Wang, H., \& Takeuchi, K. (2007). An empirical examination of the mechanisms mediating between high-performance work systems and the performance of Japanese organizations. Journal of Applied Psychology, 92, 1069-1083.

Tyler, T. R. (1989). The psychology of procedural justice: A test of the group-value model. Journal of Personality and Social Psychology, 57, 830-838.

Tyler, T. R., \& Blader, S. L. (2003). The group engagement model: Procedural justice, social identity, and cooperative behavior. Personality and Social Psychology Review, 7, 349361.

Wade, J., O’Reilly, C., \& Pollock, T. (2006). Overpaid CEOs and underpaid managers: Fairness and executive compensation. Organization Science, 17, 527-544.

Wall, T. D., Michie, J., Patterson, M., Wood, S. J., Maura, S., Clegg, C. W., \& West, M. (2004). On the validity of subjective measures of company performance. Personnel Psychology, $57,95-118$.

Youndt, M. A., Snell, S. A., Dean, J. W., \& Lepak, D. P. (1996). Human resource management, manufacturing strategy, and firm performance. Academy of Management Journal, 39, 836-866. 
Youndt, M. A., Subramaniam, O., \& Snell, S. A. (2004). Intellectual capital profiles: An examination of investments and returns. Journal of Management Studies, 41, 335-361. 
Table 1

Means, Standard Deviations, Cronbach Alphas, ICC(2)s, and Correlations among Study 1 Variables

\begin{tabular}{|c|c|c|c|c|c|c|c|c|c|c|c|c|}
\hline Variable & $\mathrm{M}$ & $\mathrm{SD}$ & 1 & 2 & 3 & 4 & 5 & 6 & 7 & 8 & 9 & 10 \\
\hline \multicolumn{13}{|l|}{ Level 1} \\
\hline 1. Employee Total (ln) & 3.04 & 1.40 & -- & & & & & & & & & \\
\hline 2. Strategic Value & 3.93 & 0.73 & $-.13^{*}$ & $(.82)$ & & & & & & & & \\
\hline 3. HPWS & 3.52 & 0.67 & -.03 & $.50^{* *}$ & -- & & & & & & & \\
\hline 4. Human Capital & 3.45 & 0.93 & -.06 & $.55^{* *}$ & $.65^{* *}$ & $(.86)$ & & & & & & \\
\hline 5. Quit Rate & 0.23 & 0.35 & $-.13^{*}$ & .04 & -.09 & -.11 & -- & & & & & \\
\hline \multicolumn{13}{|l|}{ Level 2} \\
\hline 1. Age & 5.19 & 1.80 & -- & & & & & & & & & \\
\hline 2. Data Source & .49 & .50 & $-.30^{* *}$ & -- & & & & & & & & \\
\hline 3. Food \& Beverage Sector & .27 & .44 & $-.22^{* *}$ & $.30^{* *}$ & -- & & & & & & & \\
\hline 4. Accommodation Sector & .31 & .46 & .11 & $-.41^{* *}$ & $-.41^{* *}$ & -- & & & & & & \\
\hline 5. Recreation Sector & .30 & .46 & -.02 & $.25^{* *}$ & $-.40^{* *}$ & $-.44^{* *}$ & -- & & & & & \\
\hline 6. Strategic Value mean & 4.22 & .60 & -.09 & -.05 & -.01 & -.03 & .04 & $(.74)$ & & & & \\
\hline 7. HPWS mean & 3.65 & .61 & $-.25^{* *}$ & -.01 & .00 & .03 & -.05 & $.39^{* *}$ & $(.89)$ & & & \\
\hline 8. Human Capital mean & 3.73 & .74 & -.14 & -.01 & $-.18^{*}$ & -.05 & .10 & $.47^{* *}$ & $.63^{* *}$ & $(.71)$ & & \\
\hline 9. Quit Rate mean & 0.15 & .22 & .04 & -.07 & .09 & .10 & -.14 & -.01 & $-.18^{*}$ & $-.20^{* *}$ & $(.67)$ & \\
\hline 10. Firm Performance & 3.54 & 0.86 & .06 & -.06 & .08 & -.01 & -.09 & $.15^{*}$ & $.27^{* *}$ & $.26^{* *}$ & .06 & (.89) \\
\hline
\end{tabular}

Note. Level $1 N=657$, Level $2 N=210$. Ln = natural logarithm, HPWS = High Performance Work System. Cronbach Alphas are reported in the diagonal for Level 1 variables and Firm Performance at Level 2, ICC(2)s are reported in the diagonal for the remainder of the Level 2 variables.

${ }^{*} p<.05,{ }^{* *} p<.01$ 
Table 2

Study 1: Effects of HPWS Differentiation on Firm Performance

\begin{tabular}{|c|c|c|c|}
\hline & Model 1 & Model 2 & Model 3 \\
\hline \multicolumn{4}{|c|}{ Level 1 - Human Capital outcome } \\
\hline Number of Employees (ln) & $-.05(.03)$ & $-.05(.03)$ & $-.05(.03)$ \\
\hline Strategic Value & $.40(.06)^{* *}$ & $.40(.06)^{* *}$ & $.39(.05)^{* *}$ \\
\hline HPWS & $.47(.10)^{* *}$ & $.47(.10)^{* *}$ & $.54(.08)^{* *}$ \\
\hline \multicolumn{4}{|c|}{ Level 1 -Quit Rate outcome (ln) } \\
\hline Number of Employees (ln) & $.24(.10)^{*}$ & $.24(.10)^{*}$ & $.22(.11)^{*}$ \\
\hline Strategic Value & $-.54(.19)^{* *}$ & $-.54(.19)^{* *}$ & $-.52(.20)^{* *}$ \\
\hline HPWS & $-.06(.22)$ & $-.06(.22)$ & $-.14(.25)$ \\
\hline \multicolumn{4}{|c|}{ Level 2 -Firm Performance outcome } \\
\hline Food \& Beverage Dummy & $.12(.20)$ & $.22(.21)$ & $.36(.21)$ \\
\hline Accommodation Dummy & $-.10(.20)$ & $-.05(.20)$ & $-.01(.19)$ \\
\hline Recreation Dummy & $-.16(.20)$ & $-.13(.20)$ & $-.10(.20)$ \\
\hline Data Source Dummy & $-.05(.14)$ & $-.04(.14)$ & $-.02(.14)$ \\
\hline Organization Age & $.06(.04)$ & $.06(.04)$ & $.06(.04)$ \\
\hline Strategic Value Mean & $.03(.07)$ & $-.01(.07)$ & $-.04(.07)$ \\
\hline HPWS Mean & $.30(.08)^{* * *}$ & $.22(.10)^{*}$ & $.19(.09)^{*}$ \\
\hline HC Mean & -- & $.16(.09)$ & $.28(.10)^{* *}$ \\
\hline Quit Rate Mean (ln) & -- & $.03(.03)$ & $.04(.03)$ \\
\hline HC Random Slope & -- & -- & $1.33(.48)^{* *}$ \\
\hline Quit Rate Random Slope & -- & -- & $.65(.72)$ \\
\hline
\end{tabular}

Note. Level $1 N=657$, Level $2 N=210$. HPWS = high performance work systems, HC = Human Capital. The random slope terms are either the within-firm slopes of human capital on strategic value or quit rates on strategic value estimated randomly across occupation groups. Unstandardized effects are reported. Standard errors are shown in parentheses.

${ }^{*} p<.05,{ }^{* *} p<.01$ 
Table 3

Means, Standard Deviations, Cronbach Alphas, ICC(2)s, and Correlations among Study 2 Variables

\begin{tabular}{|c|c|c|c|c|c|c|c|c|c|c|c|c|c|c|c|}
\hline Variable & M & $\mathrm{SD}$ & 1 & 2 & 3 & 4 & 5 & 6 & 7 & 8 & 9 & 10 & 11 & 12 & 13 \\
\hline \multicolumn{16}{|l|}{ Level 1} \\
\hline 1. Strategic Value & 4.15 & 0.77 & $(.76)$ & & & & & & & & & & & & \\
\hline 2. HPWS & 3.37 & 0.84 & $.47^{* *}$ & -- & & & & & & & & & & & \\
\hline \multicolumn{16}{|l|}{ Level 2} \\
\hline 1. Years Seniority & 4.74 & 4.17 & -- & & & & & & & & & & & & \\
\hline 2. Full-time & .78 & 0.41 & $.34^{* *}$ & -- & & & & & & & & & & & \\
\hline 3. Permanent Employee & .98 & 0.14 & .08 & $.19^{* *}$ & -- & & & & & & & & & & \\
\hline 4. Union member & .09 & 0.29 & .03 & .13 & .05 & -- & & & & & & & & & \\
\hline 5. Data Source & .68 & 0.47 & $-.28^{* * *}$ & $-.31^{* *}$ & -.10 & $-.32^{* *}$ & -- & & & & & & & & \\
\hline 6. Food \& Beverage Sector & .44 & 0.50 & $-.20^{* *}$ & $-.19^{* *}$ & .06 & -.14 & $.38^{* *}$ & -- & & & & & & & \\
\hline 7. Accommodation Sector & .20 & 0.40 & $.25^{* *}$ & .14 & .07 & .11 & -.14 & $-.44^{* *}$ & -- & & & & & & \\
\hline 8. Recreation Sector & .25 & 0.43 & -.02 & -.02 & $-.17^{*}$ & .06 & -.02 & $-.51^{* *}$ & $-.29^{* *}$ & -- & & & & & \\
\hline 9. HPWS mean & 3.42 & 0.79 & $.18^{*}$ & .10 & -.11 & .01 & $-.44^{* *}$ & $-.45^{* *}$ & -.02 & $.25^{* *}$ & $(.90)$ & & & & \\
\hline 10. HPWS own position & 3.45 & 0.86 & $.21^{* *}$ & $.15^{*}$ & -.10 & .01 & $-.41^{* *}$ & $-.43^{* *}$ & .03 & $.21^{* *}$ & $.94^{* *}$ & -- & & & \\
\hline 11. Fairness & 3.91 & 0.95 & .11 & .13 & .04 & -.01 & -.11 & -.09 & -.08 & .06 & $.37^{* *}$ & $.37^{* *}$ & $(.82)$ & & \\
\hline 12. Turnover Intentions & 2.41 & 1.33 & -.12 & $-.15^{*}$ & -.08 & .13 & .13 & .14 & $.19^{* *}$ & $-.15^{*}$ & $-.41^{* *}$ & $-.42^{* *}$ & $-.61^{* *}$ & $(.94)$ & \\
\hline 13. OCB & 4.09 & 0.74 & $.21^{* *}$ & $.21^{* *}$ & -.05 & -.11 & .02 & .01 & -.10 & .07 & $.22^{* *}$ & $.24^{* *}$ & $.62^{* *}$ & $-.52^{* *}$ & $(.86)$ \\
\hline
\end{tabular}

Note. Level $1 N=531$, Level $2 N=197$. HPWS = High Performance Work System, OCB = Organizational Citizenship Behavior.

ICC(2) is reported in the diagonal for HPWS mean, Cronbach Alphas are reported in the diagonal for all other variables where appropriate.

${ }^{*} p<.05,{ }^{* *} p<.01$ 

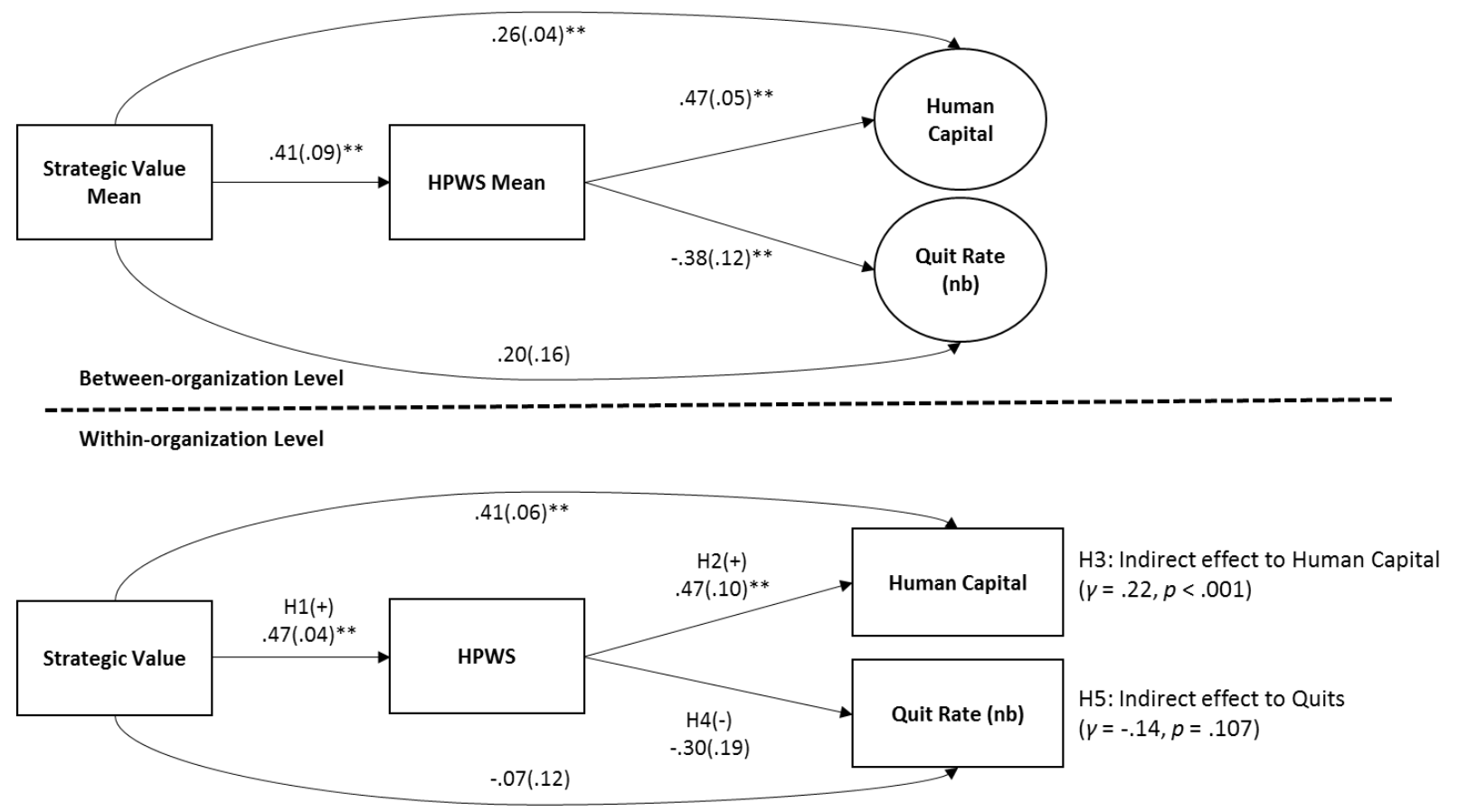

Figure 1. Study 1: Multilevel effects of strategic value on human capital and quit rates, mediated by High Performance Work Systems (HPWS).

Level $1 N=657$, Level $2 N=210$. Negative binomial (nb) regression was conducted for the quit outcome variable. The natural logarithm of the number of employees in each occupation group was controlled at the within-organization level, while the participant recruitment source (Mechanical Turk or the Canadian Tourism HR Council contact list), industry subsector, and the age of the organization were controlled at the between-organization level. Unstandardized effects are reported. Standard errors are shown in parentheses.

${ }^{*} p<.05,{ }^{* *} p<.01$ 


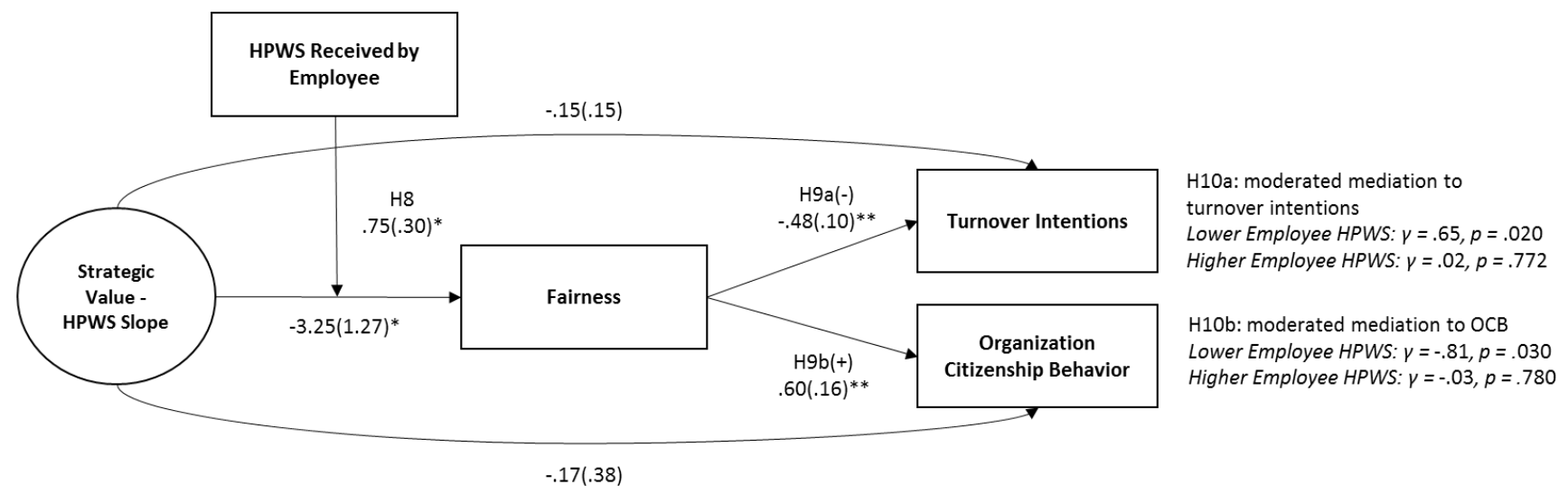

Between-Level (Strategic Value - HPWS random slope on employee attitudes and behavioral intentions)

Within-Level (rating of all occupation groups within the employees' organization)

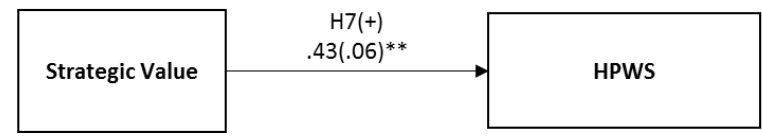

Figure 2. Study 2: Multilevel effects of strategic value and high performance work systems (HPWS) on employee turnover intentions and organizational citizenship behavior, mediated by perceived fairness.

Level $1 N=531$, Level $2 N=197$. Organization mean HPWS, the participant recruitment source (Study Response Project or Mechanical Turk), years of experience, full-time (versus part-time) employment status, permanent (versus temporary) employment status, union membership, and industry subsector we entered as controls at the between-level. Unstandardized effects are reported. Standard errors are shown in parentheses.

${ }^{*} p<.05,{ }^{* *} p<.01$. 


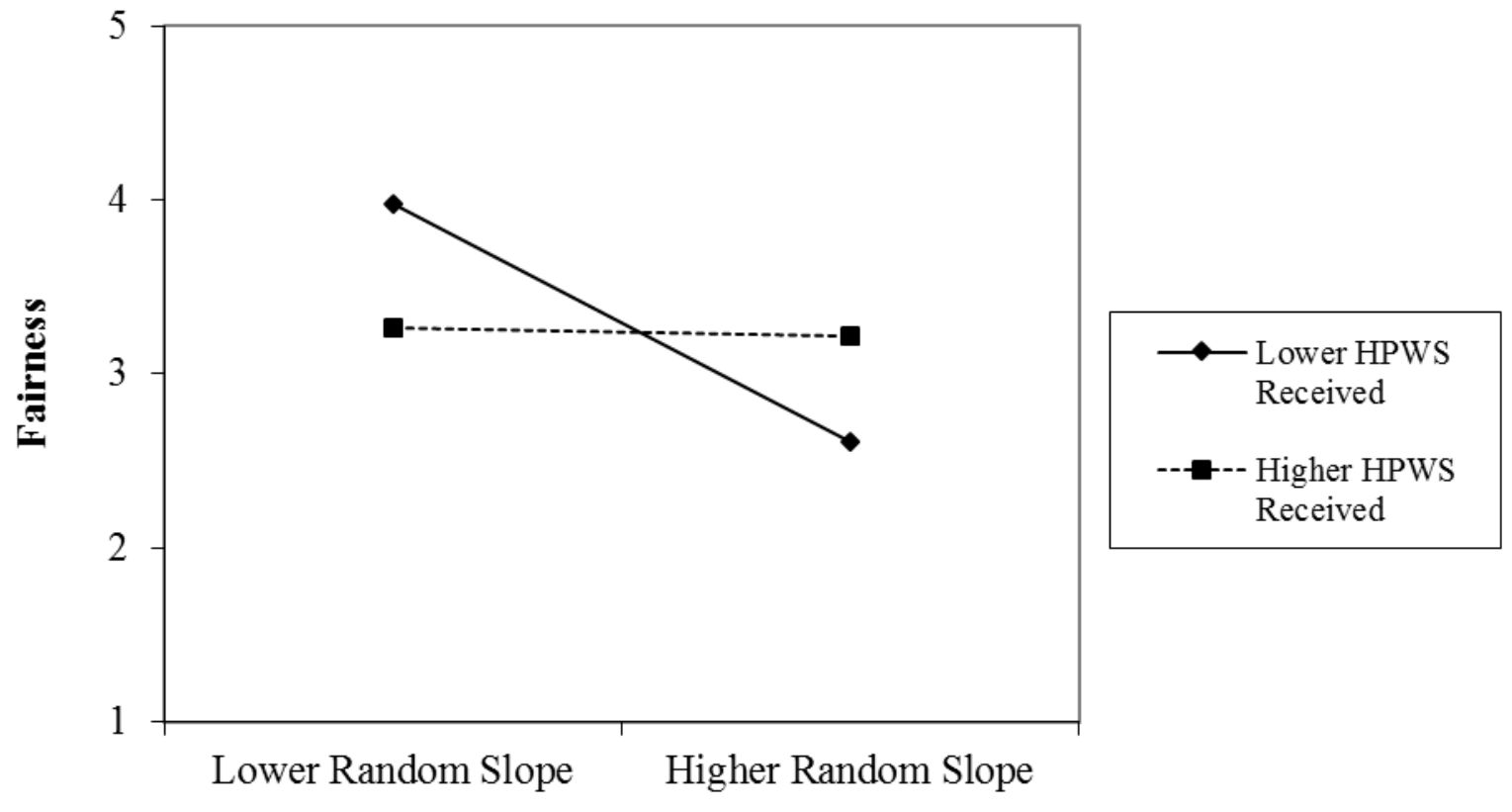

Figure 3. Study 2: Interaction between the occupation strategic value - occupation highperformance work systems (HPWS) random slope and HPWS received by the employee on perceptions of fairness. 